\title{
The Practices and Challenges of Balanced Scorecard Implementation in Municipality Service Delivery in Injibara Town Awi Zone, Ethiopia
}

\author{
Tesfaye Nigussie \\ Injibara University: College of Business and Economics, Department of marketing management, p.o.box 040, \\ Injibara, Ethiopia
}

\begin{abstract}
The purpose of this study was to assess the practices and challenges of BSC implementation at municipality service delivery at Injibara town in Awi zone, North West Ethiopia. The methodology of this research employed was both questionnaire and key informant interview. Both qualitative and quantitative data analysis method was employed. Out of the non-probability sampling purposive/judgmental sampling and census survey has been used to consider all population which is 32 . The collected data was analyzed using descriptive approach by frequencies and tables. The result of analysis revealed that there is inadequate commitment from leaders on the creation of conducive work environment, information sharing and encouragement of employees. Further, there is no close relationship with customers and failures on knowing what the stakeholders value and lack of commitment in human resource side like lack of reward system, and lack of recognition for their work are the major gaps that management should have to work more to bring improvements. Finally the researcher recommends that the organizations should have to works towards the improvements of BSC implementation by changing the mindset and attitude of employees towards BSC, motivating of employees through benefits and reward systems and automating the information handling system.
\end{abstract}

Keywords: Municipality, BSC, Implementation, Injibara town

DOI: $10.7176 / \mathrm{EJBM} / 11-4-07$

\section{Introduction}

Among many public sectors this study focuses primarily on municipal services which are rendered and controlled by urban administration. These services includes: sewage, sanitation, garbage collection and disposal, public markets, abattoir, recreational parks and cultural places, street lighting, city transport, cemeteries, urban land management, road construction, fire protection, issuance of marriage and birth, even water supply and etc. the delivery, efficiency and sufficiency of these public services are crucial in determining quality of urban environment and life. Therefore to facilitate delivery and assure efficiency of private and public sector organization, measuring their performance continuously by using transformational tools is mandatory. This resulted in the development of the BSC by Kaplan and Norton (1992), which includes both financial and nonfinancial measures. A balanced score card is a tool that translates an organization's mission and strategy into a comprehensive set of performance measures that provides the framework for a strategic measurement and management system (ibd).

Now a days, the private and public sector organizations throughout the world exercise BSC as change and strategic management system. In Ethiopia lots of public sector organizations have implemented BSC. However; the public organizations that employ BSC as change and strategic management system encountered difficulty with its design and its implementation. Hence, this study tries to assess the practices and challenges of BSC implementation at municipal service delivery in Injibara town, Awi Zone, North West Ethiopia.

\subsection{Statement of the problem}

The Public sector plays a leading role in the effective delivery of public services that are essential to the functioning of a state economy. The challenge however, has always been how to evaluate the performance of public sector organizations. With the increasing pressure for transparency, accountability and efficiency from the public and other stakeholders, it has become apparent that an evaluation method has to be implemented. Since, municipalities are the basic units of government of Ethiopia and public sector organization, developing tools that are highly effective in measuring performance is advisable to alleviate problems and to bring better contribution for economy. Therefore, using balanced scorecard performance measurement tool that has gained popularity in practice and literature relief the pressure of the problem.

However, the problem many organizations have faced is the development and application of the correct measurements that will push the strategy to improve the performance. Therefore, the researcher has seen the difficulties in implementing the BSC as it was intended. This is due to the fact that employees are bored to implement, there is resistance to change and inadequate support from leadership, lack of BSC knowledge and experience due to inadequate training, pressure of transparency and accountability, lack of linking performance 
with incentives and reward and absence of automation. Therefore, to alleviate problems and ensure the sustainable delivery of service for the community, municipality need to measure their performance from time to time and make the necessary adjustments depending on circumstantial factors by conducting timely research. Finally this research attempts to assess the practices and challenges of BSC implementation at municipal service delivery in Injibara town, Awi Zone, North west Ethiopia.

\subsection{Objectives of the study}

The objectives of this study were:

$\checkmark$ To assess the practices and the major achievements of BSC implementation.

$\checkmark$ To examine the major challenges of BSC implantation.

$\checkmark$ To assess the perception and attitudes of workers and management towards the implementation of BSC.

$\checkmark$ To identify the commitment of workers and management in the preparation and implementation of BSC.

\section{Literature review}

As a measurement system, the BSC also allows managers to review tangible results (such as financial measures), as well also intangible assets such as customer perception, innovation, motivation and brand (Christensen, 2008). The Balanced Score Card (BSC) is a carefully selected set of quantifiable measures derived from an organization's strategy and is a management tool with three main elements namely; measurement system, strategic management system and communication (Bremser and Barsky, 2004).

The main attributes of BSC are translating the vision, communicating and linking, business planning, and feedback and learning via perspectives, strategy map or causal linkages. These attributes result in to benefits such as improved alignment of strategic objectives with actions, building up a performance measurement system, aligning strategic initiatives, strengthening an organizational change process, focusing resources on strategy (Greiling, 2010; Rasoolimanesh et al.,2015). Biswas (2013) stated that the BSC comprises four segments, namely: financial, customer, internal business processes, and learning and growth. These are significant for modern organizations, even though the initial focus was more on for-profit organizations.

Balanced scorecard helps companies concentrate in two aspects: financial performance and non-financial performance, which are critical for the success, and for this reason it enables achievement of long term objectives within organizations (Niven 2003). Besides, balanced scorecard provides a comprehensive framework for the translation of strategic objective of an organization into a logical set of performance measurements, while developing strategic objectives for four perspectives, and then translating them into specific measurements (James, 2009). These measurements are communicated within businesses, including their strategy. Another benefit of balanced scorecard is assumed casual relation of the four perspectives, which makes it distinct from other systems of strategic measurements (Kaplan and Norton 1996). Causal relationship here suggest that improvement of measurements, of learning and growth lead towards improvement of internal business processes, which should cause improvement of the client measurements, until the end that the improvement of financial measurements to be achieved.

Kaplan and Norton (2000) identified the three classes of problems on the basis of empirical evidence that inhibit the creation of strategic focused organization: transitional issues, and design issues process issues. In addition to this Niven (2006), identified the top ten BSC implementation failure factors: lack of executive sponsorship, lack of BSC education and training, lack of strategy, lack of guiding rationale for BSC program, lack of reporting BSC results, inconsistent management practice, lack of new measures, ineffective team development, lack of cascading and premature links to management process. In relation to effective implementation, Niven (2002) suggests that cascading of strategy, linking the BSC to compensation, and maintaining the BSC through constant review and automated systems are critical elements.

\section{Research methodology}

\subsection{Research design}

Both qualitative and quantitative research approach would be used. A cross-sectional descriptive research design will be utilized. This means that the data for this study would be collected at one time point. The research instrument would be designed after comprehensive literature review being used to measure the research variables of interest. Both questionnaire and key informant interview were employed.

\subsection{Sampling design and techniques}

Since the target population is small in number, the researcher prefers to employ censuses survey to consider the whole population. To get the required information from the key informant especially from the management, purposive sampling technique was employed. Injibra town municipality employees were 32 hence; all employees 
were the part of the study.

\subsection{The study variables}

The study variables were basically the practices and challenges of BSC implementation in terms of leadership, strategic planning, human resource focus, organizational culture and customer and stakeholder focus.

\subsection{Data collection method}

There are two types of data sources which are usually used in research, primary and secondary data. Primary data does not actually exist until and unless it is generated through the research process. It would often be collected through techniques such as experimentation, interviewing, observation and surveys. But in this research, primary data would be collected through well designed and adapted questionnaire from sample respondents. On the other hand, Secondary sources are information sources that interpret, include, describe, or draw conclusions based on works written by others.

\subsection{Method of data analysis}

First data is collected, the collected data would be edited, coded, classified and tabulated to ensure the accuracy, completeness, assigning numerical or other symbols to answers, arranging data's in group on the basis of common characteristics and orderly or systematic presentation of numerical data respectively and finally has to be changed and interpreted into meaningful information through frequencies and percent. The data was presented by using tables. On the other hand, data gathered from the key informant interview analyzed qualitatively. Hence, the data was analyzed and processed both qualitatively and quantitatively.

\section{Results and discussion}

The analysis was made on the opinion of employees on the support of leadership, strategic planning, customer and stakeholder focus, human resource focus and organizational culture.

Table 4.1. Employee's opinion /response on the support of the leadership perspective.

\begin{tabular}{|c|l|l|l|l|l|l|l|}
\hline Items & \multicolumn{1}{|c|}{ Statements } & $\begin{array}{l}\text { Strongly dis } \\
\text { agree }\end{array}$ & disagree & Neutral & Agree & $\begin{array}{l}\text { Strongly } \\
\text { agree }\end{array}$ & $\begin{array}{l}\text { Total } \\
\text { in } \%\end{array}$ \\
\hline 1 & $\begin{array}{l}\text { Leeders share } \\
\text { information about the } \\
\text { organization }\end{array}$ & $8(25 \%)$ & $10(31.25 \%)$ & $2(6.25 \%)$ & $7(21.87 \%)$ & $5(15.6 \%)$ & 100 \\
\hline 2 & $\begin{array}{l}\text { Leaders encourage } \\
\text { learning that will help } \\
\text { us to do our job }\end{array}$ & $11(34.4 \%)$ & $5(15.6 \%)$ & $9(28.12 \%)$ & $5(15.6 \%)$ & $2(6.25 \%)$ & 100 \\
\hline 3 & $\begin{array}{l}\text { Leadres craete work } \\
\text { environment that hepls } \\
\text { us to our job }\end{array}$ & $15(46.87 \%)$ & $6(18.75 \%)$ & $4(12.5 \%)$ & $4(12.5 \%)$ & $3(9.37 \%)$ & 100 \\
\hline
\end{tabular}

(Source: researcher, 2019)

As depicted above, majority of the employees have complains on the leaders or supervisors. The result indicted that senior leaders do not create a conducive work environment, share information and do not encourage employees to learn about their job. This may seriously affect the commitment of employees in the implementation process. It is the responsibility of management to follow up and keep the interest of employees to enhance their commitment and sense of belongingness.

Table4.2. Employee's opinion/response on the preparation of strategic plan perspective.

\begin{tabular}{|c|c|c|c|c|c|c|c|}
\hline Items & Statements & $\begin{array}{l}\text { Strongly } \\
\text { dis agree }\end{array}$ & disagree & Neutral & Agree & $\begin{array}{l}\text { Strongly } \\
\text { agree }\end{array}$ & $\begin{array}{l}\text { Total } \\
\text { in } \%\end{array}$ \\
\hline 1 & $\begin{array}{ll}\text { Startegic plan are } \\
\text { prepared by the } \\
\text { participation of the } \\
\text { employees }\end{array}$ & - & - & $3((9.37 \%)$ & $9(28.12 \%)$ & $20(62.5 \%$ & 100 \\
\hline 2 & $\begin{array}{lr}\text { Startegic } & \text { focus } \\
\text { areas ( pillars of } \\
\text { excellence) are well } \\
\text { defined and understood }\end{array}$ & $5((15.6 \%)$ & $3((9.37 \%)$ & $10(31.25 \%)$ & $2(6.25 \%)$ & $12(37.5 \%)$ & 100 \\
\hline 3 & $\begin{array}{l}\text { The organization } \\
\text { knows the pains and } \\
\text { enables }\end{array}$ & - & - & $4(12.5 \%)$ & $10(31.25 \%)$ & $18(56.25 \%)$ & 100 \\
\hline
\end{tabular}

(Source: researcher, 2019) 
As depicted above, the employees have no complains on their participation at the time of strategic plan preparation, strategic focus areas are well defined and understood and organizations knows the pains/ challenges and enablers or opportunities.

Therefore, the organization should have to keep this strength part and works more towards the improvements of weak parts.

Table4.3. Employee's opinion/response on the customers and stakeholders focus

\begin{tabular}{|c|l|l|l|l|l|l|l|}
\hline Items & \multicolumn{1}{|c|}{ Statements } & $\begin{array}{l}\text { Strongly } \\
\text { dis agree }\end{array}$ & Disagree & Neutral & Agree & $\begin{array}{l}\text { Strongly } \\
\text { agree }\end{array}$ & $\begin{array}{l}\text { Total } \\
\text { in } \%\end{array}$ \\
\hline 1 & $\begin{array}{l}\text { Knowing who are the } \\
\text { customers }\end{array}$ & - & $3((9.37 \%)$ & $2(6.25 \%)$ & $10(31.25 \%)$ & $17(53.125 \%)$ & 100 \\
\hline 2 & $\begin{array}{l}\text { Keeping in touch with } \\
\text { my customers }\end{array}$ & $8(25 \%)$ & $13(40.6 \%)$ & $4(12.5 \%)$ & $5((15.6 \%)$ & $2(6.25 \%)$ & 100 \\
\hline 3 & $\begin{array}{l}\text { Knowing what } \\
\text { customers and } \\
\text { stakeholders value }\end{array}$ & $10(31.25 \%)$ & $18(56.25 \%)$ & $4(12.5 \%)$ & - & - & 100 \\
\hline
\end{tabular}

(Source: researcher, 2019)

As depicted above, the majority of employees agreed on knowing who are the customers but there is complains on keeping in touch with my customers and knowing what customers and stakeholders value. This result indicated that the organization knows their customers but fails to create close relationship with them and problems on the identification of what they value. Therefore, organization should have to work more on the improvements of such weaker areas.

Table 4.4. Employee's opinion /response on the human resource focus

\begin{tabular}{|c|l|l|l|l|l|l|l|}
\hline Items & \multicolumn{1}{|c|}{ Statements } & $\begin{array}{l}\text { Strongly dis } \\
\text { agree }\end{array}$ & Disagree & Neutral & Agree & $\begin{array}{l}\text { Strongly } \\
\text { agree }\end{array}$ & Total \\
\hline 1 & $\begin{array}{l}\text { Recognition is given for my } \\
\text { work }\end{array}$ & $19(59.375 \%)$ & $12(37.5 \%)$ & $1(3 \%)$ & & - & 100 \\
\hline 2 & There is safe work place & $24(75 \%)$ & $7(22 \%)$ & - & $1(3 \%)$ & - & 100 \\
\hline 3 & $\begin{array}{l}\text { The organization and } \\
\text { management care about me }\end{array}$ & $12(37.5 \%)$ & $14(43.75 \%)$ & $4(12.5 \%)$ & $2(6.25 \%)$ & - & 100 \\
\hline
\end{tabular}

(Source: researcher, 2019)

As shown above, the employees have complains on recognition is given for my work, there is safe work place and the organization and management care about me. This indicated that the organization didn't give recognition for the work of employees, there work place is not safe and care is not given the employees.

Table4.5. Employee's opinion /response on organization and culture

\begin{tabular}{|c|l|l|l|l|l|l|l|}
\hline Items & Statements & $\begin{array}{l}\text { Strongly dis } \\
\text { agree }\end{array}$ & Disagree & Neutral & Agree & $\begin{array}{l}\text { Strongly } \\
\text { agree }\end{array}$ & $\begin{array}{c}\text { Total } \\
\text { in } \%\end{array}$ \\
\hline 1 & $\begin{array}{l}\text { The organization } \\
\text { rewards success }\end{array}$ & $25(78.125 \%)$ & $3(9.37 \%)$ & $4(12.5 \%)$ & & - & 100 \\
\hline 2 & $\begin{array}{l}\text { The organization helps } \\
\text { me to help my } \\
\text { community }\end{array}$ & $11(34.375 \%)$ & $16(50 \%)$ & $3(9.37 \%)$ & $2(6.25 \%)$ & - & 100 \\
\hline 3 & $\begin{array}{l}\text { The organization has } \\
\text { work standards and } \\
\text { ethics }\end{array}$ & $3(9.37 \%)$ & $5((15.6 \%)$ & $2(6.25 \%)$ & $10(31.25 \%)$ & $12(37.5 \%)$ & 100 \\
\hline
\end{tabular}

(Source: researcher, 2019)

As shown above, employees have doubt on the reward success and organizational encouragement to help employees to help their community. But majority of employees agreed about the standards and ethics of organization. The result indicated that the organization didn't reward and encourage the employees.

\subsection{Discussion of interview result}

Interviews were also conducted with municipality top management and some selected employees. The interviews were basically considered two questions. Therefore, this section presents the result of each interview questions.

The first questions forwarded to the some selected employees and management was about the challenges of BSC implementation. In this regard, the interviewee's response was the following:

\footnotetext{
$\checkmark$ Poor linkage of the BSC result to reward system

$\checkmark$ Poor monitoring and evaluation system

$\checkmark$ Subjectivity and favoritism in evaluation
} 


\section{$\checkmark \quad$ Insufficient training on BSC \\ $\checkmark$ Lack of setting the right performance measurement indicators \\ $\checkmark$ Poor information management and communication \\ $\checkmark$ There is commanding only \\ $\checkmark$ Employees are considered as burden holders}

The second interview question asked was what benefits did your organization obtained by the implementation of BSC. In this regard, they replied that, the organization really benefited by the implementation of BSC. For example:
* Organizational focus areas have been identified
* Performance has been improved
* Service delivery has been improved
* Day to day activities of each employee have been aligned with the strategy
* Interactive communication have been created
* Creating accountability and transparency

\subsection{Summary of Findings}

Based on the result of analysis made, the summary of major findings were as follows:

As far the leadership perspective is concerned, the result indicted that senior leaders do not create a conducive work environment, share information and do not encourage employees to learn about their job. This may seriously affect the commitment of employees in the implementation process.

As far the strategic plan is concerned, the employees have agreed on their participation at the time of strategic plan preparation, strategic focus areas are well defined and understood and organizations know the pains/ challenges and enablers or opportunities.

As far the customers and stakeholders focus, the result indicated that the organization knows their customers but fails to create close relationship with them and problems on the identification of what they value.

As the human resource is concerned, the result indicated that the organization didn't give recognition for the work of employees, there work place is not safe and care is not given the employees.

As far the organization and culture is concerned, result indicated that the organization didn't reward and encourage the employees but majority of employees have agreed about having standards and ethics of organization.

\subsection{Conclusion}

In short, the implementation of BSC facilitated changes in strategic direction of the organization; it has improved the focus for effecting strategic change and improved accomplishment of tasks that represents the foundation of good performance management. In adequate commitment of leaders or organization in general impeded the effectiveness of the BSC in achieving intended objectives.

Top management support for BSC implementation effort has great importance in distinguishing between its ultimate success and failure. Further the degree of management support for the BSC will lead to significant variations in the degree of acceptance or resistance to the BSC.

\subsection{Recommendation}

Based on the findings that was obtained with regard to the practices and challenges of BSC at municipality service delivery office of injibara town in awi zone, the following recommendations were given for the organization to benefit from BSC implementation and for taking corrective measures:

$>$ The organization should work on building its internal capacity and developing BSC trainers and consultants.

$>$ Working more on changing the mindset and attitude of employees towards BSC

$>$ Strengthening the BSC training and communication or encouraging employee's participation at the time of strategic plan preparation.

$>$ Work more on the motivation of employees through benefits and reward systems.

$>$ Improve and develop management information system (automation).

$>$ Setting best practice sharing forum

$>$ Develop consistent and strong leadership

$>$ Give recognition for the work of employees

\subsection{Recommendations for the future research}

This research was only delimited to municipality of injibara town in Awi Zone on the practices and challenges of BSC implementation. Therefore, further research is in need to consider other unseen areas or towns in Awi zone in particular and other regions of the country in general. 


\section{References}

* Al Sawalqa, F., Holloway, D., \& Alam, M. (2011). Balanced Scorecard implementation in Jordan: An initial analysis. International Journal of Electronic Business Management, 9(3), 196.

* Biswas, B. (2013). Compensation and Benefit Design: Applying Finance and Accounting Principles to global HRMs. Upper Saddle River, NJ: Financial Times/Prentice hall; London: Pearson Education Distributor.

* Bremser, W. G., \& Barsky, N. P. (2004). Utilizing the balanced scorecard for R\&D performance measurement. R\&D Management, 34(3), 229-238.

* Christensen, D. A. (2008). The Impact of Balanced Scorecard Usage on Organization Performance. Pro Quest.

* Cooper Donald and Schindler Pamela,( 2003). Business Research method.. 8th ed. : Mc Graw-Hill higher education.

* Greiling, D. (2010). Balanced Scorecard Implementation in German non-profit Organisations. International Journal of productivity and Performance Management, 59(6):534-554.

* Ittner, D. C and Lacker, D.F. (2003). Innovations in Performance Measurement: Trends and Research Implications. Journal of Management Accounting Research, ProQuest: 205-238.

* Kaplan, R.S and Norton, D.P. (2206). The strategy focused organization: How BSC companies thrive to the business environment, Boston, Massachusetts Harvard business school publishing corp.

* Kaplan, R.S and Norton, D.P. (1992). The Balanced Scorecard- Measures that Drive to Performance. Harvard Business Review, 69-79. Available at: http:/e3idocs.fmhs.fastmail.net/the balancedscorecard.pdf. Accessed on 14 November 2013.

* Kaplan, R. S. and D. P. Norton (1996). The Balanced Scorecard: Translating Strategy into Action. Boston: Harvard Business Review, Jan- Feb, 75- 85.

* Niven, P.R. (2002). Balanced Scorecard Step-by-step: Maximizing Performance and Maintaining Results. New York: John Wiley \& Sons, Inc.

* Niven, P.R. (2006). Balanced Scorecard Step-by-step: Maximizing Performance and Maintaining Results. $2^{\text {nd }}$ ed. New York: John Wiley \& Sons, Inc.

* Ramuvhundu, M.N. (2012). Evaluating the Impact of Local Government Performance Management Systems on Service Delivery. A Research Report Presented to the Graduate School of Business in Partial Fulfillment of the requirements for the degree of Master of Business Administration (MBA). University of South Africa, Midrand.

* Rasoolimanesh, S.M., Jaafar, M and Badarulzaman, M.N. (2015). Investigating a Framework to Facilitate the Implementation of City Development Strategy Using Balanced Scorecard. Habitat International, 46:156165.

* Saunders, m. N. A., (2003). Organization justice, Trust and the managment of change.. An exploration of personal review, Volume 32 No.3, pp. 360-375. 